\title{
Synthesis of Polydiacetylenes from Novel Monomers Having Two Diacetylene Units Linked by an Arylene Group
}

\author{
Hiroshi MatsuzaWa, Shuji OKada, Abhijit Sarkar, Hiro Matsuda, ${ }^{*}$ and Hachiro NaKanishi \\ Institute for Chemical Reaction Science, Tohoku University, 2-1-1 Katahira, Sendai 980-8577, Japan \\ ${ }^{*}$ National Institute of Materials and Chemical Research, 1-1 Higashi, Tsukuba 305-8565, Japan
}

(Received September 14, 2000; Accepted October 19, 2000)

\begin{abstract}
Three novel monomers 4BCMU4A(Ar) with chemical structures of $\mathrm{R}-\mathrm{C} \equiv \mathrm{C}-\mathrm{C} \equiv \mathrm{C}-\mathrm{Ar}-\mathrm{C} \equiv \mathrm{C}-\mathrm{C} \equiv \mathrm{C}-\mathrm{R}$, where $\mathrm{R}=-\left(\mathrm{CH}_{2}\right)_{4}-\mathrm{OCONHCH}_{2} \mathrm{COOC}_{4} \mathrm{H}_{9}$ and $\mathrm{Ar}=1,4$-phenylene $(\mathrm{Ph})$ or 2,3,5,6-tetrafluoro-1,4-phenylene $(\mathrm{PhF})$ or 4,4'biphenylene (Biph), were synthesized. $4 \mathrm{BCMU} 4 \mathrm{~A}(\mathrm{Ph})$ was found to be stable for solid-state polymerization, although $4 \mathrm{BCMU} 4 \mathrm{~A}(\mathrm{PhF})$ and $4 \mathrm{BCMU} 4 \mathrm{~A}(\mathrm{Biph})$ could be polymerized by UV or $\gamma$-ray irradiation. The polymerization for two polymerizable monomers was investigated in detail mainly by solid-state ${ }^{13} \mathrm{C} N M R$. The polymerization of $4 \mathrm{BCMU} 4 \mathrm{~A}(\mathrm{PhF})$ and $4 \mathrm{BCMU} 4 \mathrm{~A}(\mathrm{Biph})$ took place by 1,4 -addition reaction at one of the butadiyne moieties in the monomer to give singlechain-type polydiacetylenes with the respective butadiynylaryl moiety as a side chain and ladder-type ones were not obtained. High crystallinity was confirmed for these polymers by X-Ray diffraction. Polydiacetylene obtained from 4BCMU$4 \mathrm{~A}(\mathrm{PhF})$ was found to be dispersed in organic solvent. Visible absorption spectra of this polymer in dispersion state with different compositions of solvents and in amorphous state were investigated in comparison with the spectrum in the crystalline state.
\end{abstract}

KEY WORDS Bis(butadiynyl)arene / Solid-State Polymerization / Polydiacetylene /

Polydiacetylenes (PDAs) are a unique class of $\pi$ conjugated polymers obtainable by solid-state $1,4-$ addition polymerization of diacetylenes (DAs). ${ }^{1,2}$ The polymerization is usually stimulated by UV or $\gamma$-ray or annealing. Since the reaction is topochemically controlled, the reactivity of DAs is greatly affected by packing in crystals. ${ }^{3}$ In fact, when those DAs in crystals have stacking distance $d$ of adjacent molecules in the array of about $5 \AA$ and angle $\Phi$ between the DA rod and stacking axis of about $45^{\circ}, 1,4$-addition polymerization occurs (Scheme 1). Since molecular packing in crystals is determined by the substituents attached to the DA moiety, the substituents affect the reactivity of the DAs by physical disposition rather than chemical nature. In this connection, much research has been performed to explore the relationship between structure and reactivity of DAs. ${ }^{1-4}$

PDAs are important for topochemical polymerization studies. Much research on physical properties of PDA such as electrical, ${ }^{5}$ chromic, ${ }^{6}$ and nonlinear optical (NLO) properties, ${ }^{7}$ which originate from its quasi-one dimensional $\pi$-conjugated backbone structure, has been undertaken. Especially, third-order NLO properties of PDAs have attracted interest. ${ }^{8-10}$ To achieve larger $\chi^{(3)}$ on PDA, several PDAs have been proposed and synthesized with tailor-made molecular design by the following two ways. One is the extension of $\pi$-conjugation system and the other is increase of $\pi$-conjugated polymer backbone density. ${ }^{11-19}$ For the extension of $\pi$-conjugation, the introduction of $\pi$-conjugated substituents directly attached to the PDA backbone seems indispensable. ${ }^{15}$ Direct attachment of aromatic ${ }^{16}$ or acetylenic ${ }^{17}$ substituents to the polymer backbone for the single-chain PDAs is effective to modify the electronic structure of the polymer backbone resulting in enhancement of $\chi^{(3)}{ }^{(3,19}$ For increase of $\pi$-conjugated polymer backbone density, ladder-type PDAs as shown in Scheme 2 are promising, because $\pi$-conjugation density is at least almost doubled simply due to increase in PDA backbones per monomer unit when the monomer molecular length is fixed. Thus, we synthesized several monomers for the ladder-type PDA having an inner substituent (X) between two DA moieties with outer substituents $(R) .{ }^{11-14}$

We designed and synthesized three novel monomers with 1,4-phenylene or 2,3,5,6-tetrafluoro-1,4-phenylene or 4,4'-biphenylene as inner substituents $\mathrm{X}$ and alkoxycarbonylmethylurethane (AU: $-\left(\mathrm{CH}_{2}\right)_{4}-\mathrm{OCONHCH}_{2}$ $\left.\mathrm{COO}-\left(\mathrm{CH}_{2}\right)_{4}-\mathrm{H}\right)$ groups as outer substituents $\mathrm{R}$ in the present work. The AU group was selected because hydrogen bonding between AU groups in adjacent monomers is expected to form rigid crystalline structure, resulting in smooth solid-state polymerization. If both butadiyne moieties of these monomer can be polymerized, the ladder-type PDA in Scheme 2 with $\pi$-conjugation between two polymer backbones may be produced. Even if only one butadiyne moiety in a monomer is polymerized to give single-chain-type PDAs, $\pi$-conjugation effect of

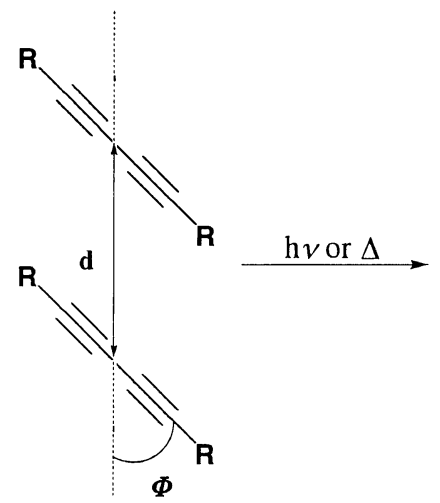

Diacetylene monomer

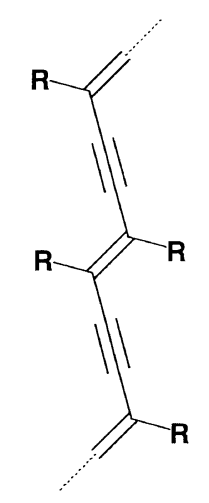

Polydiacetylene
Scheme 1. Polymerization scheme of DA monomers. When the condition for monomer array in solid state is satisfied, where the distance $d$ and angle $\Phi$ are about $5 \AA$ and $45^{\circ}$, polymerization occurs at 1,4-position to give PDA. 


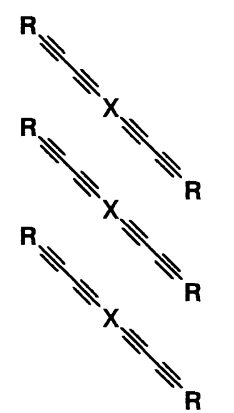

Monomer

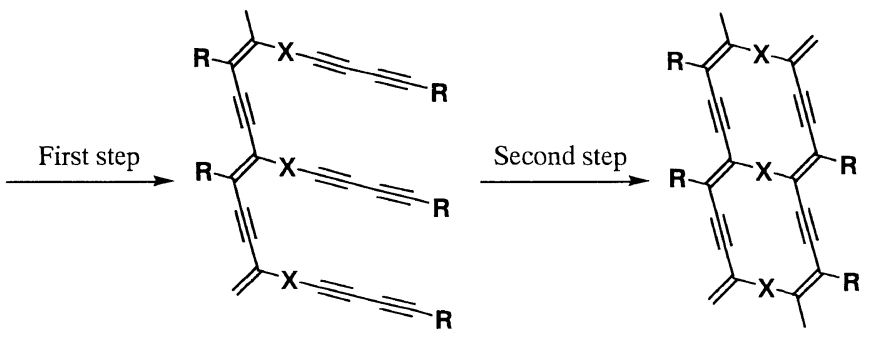

Single-chain-type PDA
Ladder-type PDA

Scheme 2. Polymerization scheme of monomers with two DA moieties modified by an inner linkage X and two outer substituents R.
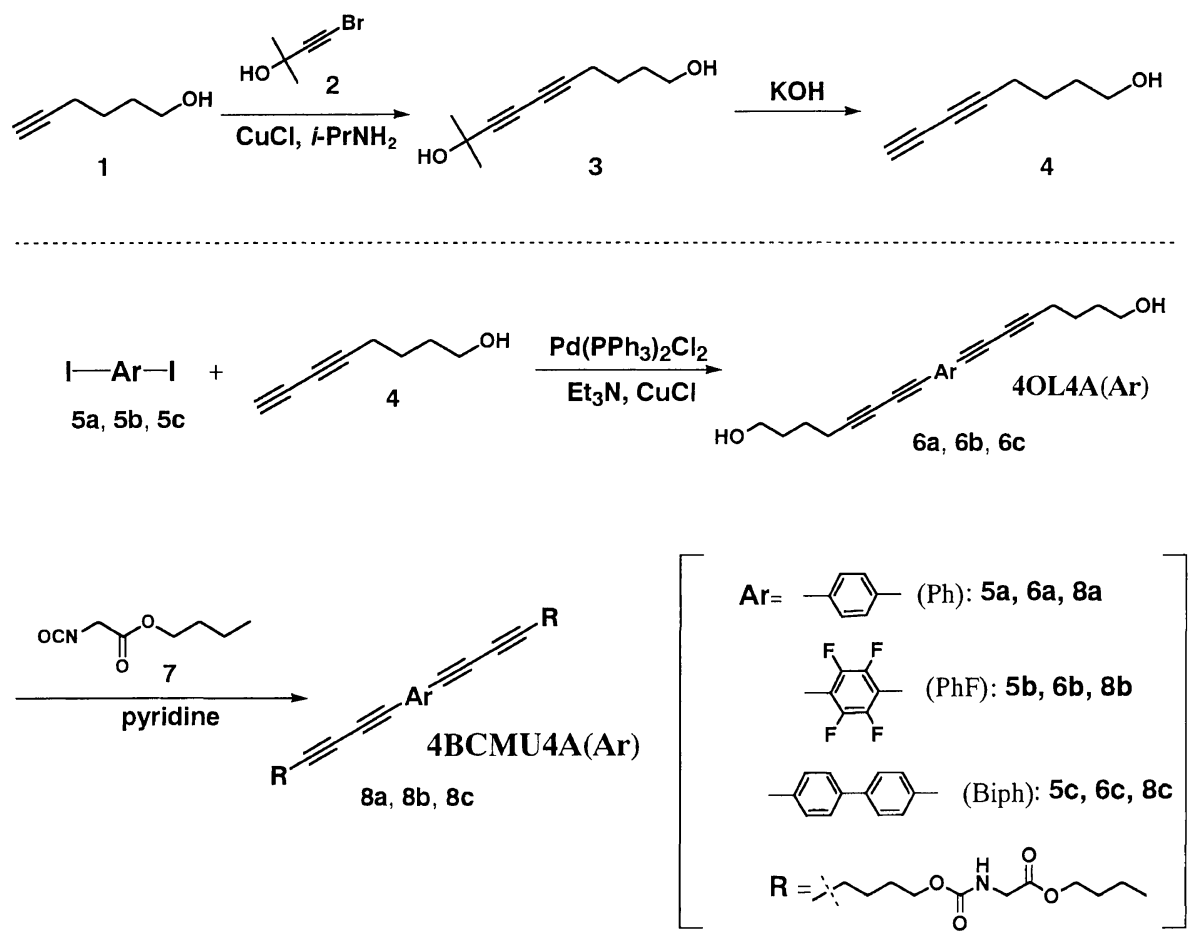

Scheme 3. Synthetic scheme for 4BCMU4A(Ar) monomers.

the aromatic substituents to polymer backbone improve optical properties compared with conventional PDAs. This paper reports the synthesis of the monomers mentioned above, and mechanisms of polymer formation as well as structures of the polymers. We used various techniques such as solid-state ${ }^{13} \mathrm{C}$ nuclear magnetic resonance (NMR) spectroscopy, Fourier transform infrared (FT-IR) spectroscopy and powder X-Ray diffraction (XRD). Absorption spectra were used to characterize the polymers. Since one of the polymers forms dispersion in organic solvent, absorption properties for this dispersion state were studied.

\section{EXPERIMENTAL}

Scheme 3 shows the synthetic route of investigated monomers 8a-8c, abbreviated as 4BCMU4A(Ar). Solvents and reagents in this work were purified according to standard literature techniques. ${ }^{20}$ Commercially avail- able 5-hexyn-1-ol (Lancaster), 1,4-diiodobenzene (Kanto Chemical), 1,4-diiodo-2,3,5,6-tetrafluorobenzene, 4,4'diiodobiphenyl (Aldrich) and butyl isocyanatoacetate (Tokyo Kasei Kogyo) were used as obtained. Preparation of 5,7-octadiyn-1-ol 4 was carried out according to a similar procedure reported earlier. ${ }^{21}$ Purification of the synthesized compounds was done by column chromatography using 300-mesh silica gel. Thin layer chromatography (TLC) of silica gel was used to monitor the reactions. Melting points were measured on a Yanaco MP-500 micro melting points apparatus without correction. UV/visible/near-infrared absorption spectra were measured using a JASCO V-570 spectrophotometer. FT-IR spectra were recorded on a Shimadzu FTIR- $8100 \mathrm{M}$ spectrometer. ${ }^{1} \mathrm{H}$ and ${ }^{13} \mathrm{C}$ NMR in solution were recorded on a JEOL JNM-LA 400 spectrometer referring tetramethylsilane as an internal standard. ${ }^{13} \mathrm{C}$ solid-state highresolution spectra were obtained using a Bruker MSL300 spectrometer with cross-polarization/magic angle 
spinning (CP/MAS) method. For CP/MAS spectra, the $\mathrm{CH}_{2}$ peak of external adamantane was set at $29.5 \mathrm{ppm}$ from tetramethylsilane as a ${ }^{13} \mathrm{C}$ chemical shift. Spinning sidebands in solid-state NMR spectra were verified using a TOSS (total suppression of spinning sidebands) pulse sequence, and were clearly distinguishable. The powder X-Ray diffraction (XRD) patterns were recorded on a Mac Science M18 $\mathrm{XHF}^{22}{ }_{-}$SRA using $\mathrm{Cu}-K_{\alpha}$ radiation.

Synthesis of 1,4-Bis(8-hydroxy-1,3-octadiynyl)benzene (4$O L 4 A(P h)) 6 \boldsymbol{a}$

A solution of $4(0.78 \mathrm{~g}, 6.39 \mathrm{mmol})$ in triethylamine (45 $\mathrm{mL}$ ) was prepared under nitrogen at ambient temperature. 1,4-Diiodobenzene $\mathbf{5 a}(1.00 \mathrm{~g}, 3.03 \mathrm{mmol})$, powdered dichlorobis(triphenylphosphine)palladium(II) (41 $\mathrm{mg}$ ) and copper(I) chloride (12 mg) were added to the solution. After stirring overnight, the solvent was removed under reduced pressure and dilute hydrochloric acid was added to the residue. After extraction with ether and separation of the layers, the organic layer was washed with saturated sodium chloride aqueous solution and dried over anhydrous magnesium sulfate. After removing the solvent, purification was performed by column chromatography (chloroform to chloroform:ethyl acetate / $10: 1$ to $3: 1$ ). The first fraction contained a monosubstituted compound, namely, 8-(4-iodophenyl)-5,7octadiyn-1-ol $(0.35 \mathrm{~g}$, yield $36 \%)$ as a white powder. The second fraction gave $4 \mathrm{OL} 4 \mathrm{~A}(\mathrm{Ph}) \mathbf{6 a}(0.43 \mathrm{~g})$ as a white powder. Yield: $45 \%$. Mp: $137.5-139^{\circ} \mathrm{C} .{ }^{1} \mathrm{H}$ NMR $(400$ $\left.\mathrm{MHz} \mathrm{CDCl}_{3}\right): \delta 1.28(2 \mathrm{H}, \mathrm{t}, J=5.9 \mathrm{~Hz}), 1.64-1.76(8 \mathrm{H}$, $\mathrm{m}), 2.43(4 \mathrm{H}, \mathrm{t}, J=6.7 \mathrm{~Hz}), 3.70\left(4 \mathrm{H}, \mathrm{dt}, J=5.4 \mathrm{~Hz}, J^{\prime}=\right.$ $5.9 \mathrm{~Hz}), 7.39(4 \mathrm{H}, \mathrm{s}) .{ }^{13} \mathrm{C} \mathrm{NMR}\left(100 \mathrm{MHz}, \mathrm{CDCl}_{3}\right): \delta$ $19.43,24.50,31.70,62.26,65.33,74.24,76.60,85.66$, 122.45, 132.36. IR (KBr), $\mathrm{cm}^{-1}: 3352,2948,2865,1508$, 1049, 983. Calcd for $\mathrm{C}_{22} \mathrm{H}_{22} \mathrm{O}_{2}$ : C, 82.98; H, 6.96. Found: C, 82.99; H, 7.05 .

\section{Synthesis of 2,3,5,6-Tetrafluoro-1,4-bis(8-hydroxy-1,3-} octadiynyl)benzene (4OL4A(PhF)) $6 \boldsymbol{b}$

The preparation method was similar to $\mathbf{6 a}$, using $1,4-$ diiodo-2,3,5,6-tetrafluorobenzene $\mathbf{5 b}$ instead of $\mathbf{5 a}$. In this case, the reaction was carried out for $20 \mathrm{~h}$. Upon purification by column chromatography, the first fraction contained a mono-substituted compound, namely, 8-(4iodo-2,3,5,6-tetrafluorophenyl)-5,7-octadiyn-1-ol (yield $23 \%$ ) as a white powder. The second fraction gave 4OL4$\mathrm{A}(\mathrm{PhF}) \mathbf{6 b}$ as a white powder. Yield:44\%. Mp: 149$151^{\circ} \mathrm{C} .{ }^{1} \mathrm{H} \mathrm{NMR}\left(400 \mathrm{MHz}, \mathrm{CDCl}_{3}\right): \delta 1.44(2 \mathrm{H}$, broad), $1.66-1.75(8 \mathrm{H}, \mathrm{m}), 2.47(4 \mathrm{H}, \mathrm{t}, J=6.6 \mathrm{~Hz}), 3.70(4 \mathrm{H}, \mathrm{t}, J$ $=5.8 \mathrm{~Hz}) \cdot{ }^{13} \mathrm{C} \mathrm{NMR}\left(100 \mathrm{MHz}, \mathrm{CDCl}_{3}\right): \delta 19.48,24.27$, $31.64,59.43,62.06,64.74,87.66,89.72,104.55(\mathrm{~m})$, 147.70 (dddd, $\left.J_{\mathrm{CF}}=256,16,7,4 \mathrm{~Hz}\right)$. IR $(\mathrm{KBr}), \mathrm{cm}^{-1}$ : $3290,2926,2865,2251,1493,1059,984$. Calcd for $\mathrm{C}_{22^{-}}$ $\mathrm{H}_{18} \mathrm{~F}_{4} \mathrm{O}_{2}$ : C, 67.69; H, 4.65. Found: C, 67.78; H, 4.62.

\section{Synthesis of Biphenyl-4,4'-bis(8-hydroxy-1,3-octadiynyl) (4OL4A(Biph)) $6 \mathrm{c}$}

This preparation was similar to $\mathbf{6 a}$, using $4,4^{\prime}$ diiodobiphenyl 5c instead of $\mathbf{5 a}$. The reaction was carried out for $6 \mathrm{~h}$ at $60^{\circ} \mathrm{C}$. Upon purification by column chromatography, the first fraction contained a monosubstituted compound, namely, 8-(4'-iodobiphenyl)-5,7- octadiyn-1-ol (yield 13\%) as a white powder. The second fraction gave $4 \mathrm{OL} 4 \mathrm{~A}(\mathrm{Biph}) \mathbf{6 c}$ as a white powder. Yield: 52\%. Mp: $240-241^{\circ} \mathrm{C} .{ }^{1} \mathrm{H}$ NMR $\left(400 \mathrm{MHz}, \mathrm{CDCl}_{3}\right): \delta$ $1.28(2 \mathrm{H}$, broad), $1.65-1.78(8 \mathrm{H}, \mathrm{m}), 2.44(4 \mathrm{H}, \mathrm{t}, J=6.6$ $\mathrm{Hz}), 3.71(4 \mathrm{H}, \mathrm{t}, J=5.6 \mathrm{~Hz}), 7.52(4 \mathrm{H}, \mathrm{d}, J=8.9 \mathrm{~Hz})$, $7.55(4 \mathrm{H}, \mathrm{d}, J=8.9 \mathrm{~Hz}) .{ }^{13} \mathrm{C}$ NMR $\left(100 \mathrm{MHz} \mathrm{CDCl}_{3}\right): \delta$ $19.62,25.56,32.73,61.73,65.79,74.97,76.09,86.34$, 122.16, 127.91, 133.83, 141.16. IR (KBr), $\mathrm{cm}^{-1}: 3319$, 2940, 2865, 1061, 822. Calcd for $\mathrm{C}_{28} \mathrm{H}_{26} \mathrm{O}_{2}$ : C, 85.24; $\mathrm{H}$, 6.64. Found: C, 84.91; H, 6.78.

Synthesis of 8,8'-(1,4-Phenylene)bis(5,7-octadiynyl ( $N$ butoxycarbonylmethyl)carbamate) (4BCMU4A(Ph)) $8 \boldsymbol{a}$

A solution of $6 \mathbf{a}(0.42 \mathrm{~g}, 1.35 \mathrm{mmol})$ in toluene $(40 \mathrm{~mL})$ was heated to $80^{\circ} \mathrm{C}$. Butyl isocyanatoacetate $7(0.45 \mathrm{~g}$, $2.86 \mathrm{mmol})$ and pyridine $(0.25 \mathrm{~mL})$ were added to the solution and the mixture was stirred for $18 \mathrm{~h}$ at $80^{\circ} \mathrm{C}$. After removing the solvent, purification by column chromatography (chloroform) gave $4 \mathrm{BCMU} 4 \mathrm{~A}(\mathrm{Ph}) \mathbf{8 a}(0.52 \mathrm{~g})$ as a white powder. Yield: $61 \%$. Mp: $119-120^{\circ} \mathrm{C} .{ }^{1} \mathrm{H}$ NMR $\left.\left(400 \mathrm{MHz}^{\mathrm{CDCl}}\right)_{3}\right): \delta 0.94(6 \mathrm{H}, \mathrm{t}, J=7.5 \mathrm{~Hz}), 1.38(4 \mathrm{H}$, $\mathrm{m}), 1.61-1.82(12 \mathrm{H}, \mathrm{m}), 2.42(4 \mathrm{H}, \mathrm{t}, J=7.0 \mathrm{~Hz}), 3.96(4$ $\mathrm{H}, \mathrm{d}, J=5.4 \mathrm{~Hz}), 4.13(4 \mathrm{H}, \mathrm{t}, J=7.1 \mathrm{~Hz}), 4.16(4 \mathrm{H}, \mathrm{t}, J=$ $6.7 \mathrm{~Hz}), 5.14\left(2 \mathrm{H}\right.$, broad), $7.40(4 \mathrm{H}, \mathrm{s}) .{ }^{13} \mathrm{C} \mathrm{NMR}(100$ $\mathrm{MHz}, \mathrm{CDCl}_{3}$ ): $\delta 13.58,18.94,19.22,24.53,28.01,30.43$, $42.61,64.50,65.25,65.39,74.20,76.53,85.25,122.36$, $132.29,156.39,170.12$. IR (KBr), $\mathrm{cm}^{-1}$ : 3345, 2962, 2871, 1757, 1694, 1536, 841. Calcd for $\mathrm{C}_{36} \mathrm{H}_{44} \mathrm{~N}_{2} \mathrm{O}_{8}$ : C, 68.33; H, 7.01; N, 4.42. Found: C, 68.07; H, 6.98; N, 4.21.

Synthesis of 8,8'-(2,3,5,6-Tetrafluoro-1,4-phenylene)bis(5,7-octadiynyl (N-butoxycarbonylmethyl)carbamate) (4$B C M U 4 A(P h F)) 8 b$

The procedure for preparation was similar to $\mathbf{8 a}$, using $6 \mathbf{b}$ instead of $6 \mathbf{a}$. The reaction was carried out for $16 \mathrm{~h}$ at $80^{\circ} \mathrm{C}$. Yield: $85 \%$. Mp: $139.5-141^{\circ} \mathrm{C} .{ }^{1} \mathrm{H}$ NMR $(400 \mathrm{MHz}$, $\left.\mathrm{CDCl}_{3}\right): \delta 0.94(6 \mathrm{H}, \mathrm{t}, J=7.5 \mathrm{~Hz}), 1.35-1.82(16 \mathrm{H}, \mathrm{m})$, $2.46(4 \mathrm{H}, \mathrm{t}, J=6.7 \mathrm{~Hz}), 3.96(4 \mathrm{H}, \mathrm{d}, J=5.4 \mathrm{~Hz}), 4.13$ $(4 \mathrm{H}, \mathrm{t}, J=6.7 \mathrm{~Hz}), 4.16(4 \mathrm{H}, \mathrm{t}, J=6.7 \mathrm{~Hz}), 5.15(2 \mathrm{H}$, broad). ${ }^{13} \mathrm{C}$ NMR $\left(100 \mathrm{MHz}, \mathrm{CDCl}_{3}\right): \delta 13.58,18.97$, $19.34,24.32,28.06,30.47,42.64,59.50,64.45,64.90$, $65.30,87.65,89.32,104.52(\mathrm{~m}), 147.67$ (dddd, $J_{\mathrm{CF}}=254$, $17,8,5 \mathrm{~Hz}), 156.40,170.13$. IR (KBr), $\mathrm{cm}^{-1}: 3359,2961$, $2870,2246,1717,1690,1491,1213,1051$. Calcd for $\mathrm{C}_{36^{-}}$ $\mathrm{H}_{40} \mathrm{~F}_{4} \mathrm{~N}_{2} \mathrm{O}_{8}$ : C, 61.35; H, 5.72; N, 3.98. Found: C, 61.08; $\mathrm{H}, 5.70 ; \mathrm{N}, 4.01$.

Synthesis of 8,8'-Biphenyl-4,4'-bis(5,7-octadiynyl ( $N$ butoxycarbonylmethyl)carbamate) (4BCMU4A(Biph)) $8 c$

The preparation was similar to $\mathbf{8 a}$, using $\mathbf{6 c}$ instead of 6a. The reaction was carried out for $13 \mathrm{~h}$ at $90^{\circ} \mathrm{C}$. Yield: 50\%. Mp: $149.5-151^{\circ} \mathrm{C} .{ }^{1} \mathrm{H}$ NMR $\left(400 \mathrm{MHz}, \mathrm{CDCl}_{3}\right): \delta$ $0.94(6 \mathrm{H}, \mathrm{t}, J=7.4 \mathrm{~Hz}), 1.34-1.83(16 \mathrm{H}, \mathrm{m}), 2.43(4 \mathrm{H}, \mathrm{t}$, $J=7.0 \mathrm{~Hz}), 3.97(4 \mathrm{H}, \mathrm{d}, J=5.6 \mathrm{~Hz}), 4.13(4 \mathrm{H}, \mathrm{t}, J=6.4$ $\mathrm{Hz}), 4.16(4 \mathrm{H}, \mathrm{t}, J=6.7 \mathrm{~Hz}), 5.14(2 \mathrm{H}$, broad $), 7.52(4 \mathrm{H}$, $\mathrm{d}, J=8.8 \mathrm{~Hz}), 7.55(4 \mathrm{H}, \mathrm{d}, J=8.8 \mathrm{~Hz}) .{ }^{13} \mathrm{C}$ NMR $(100$ $\mathrm{MHz} \mathrm{CDCl}_{3}$ ): $\delta 13.63,19.00,19.27,24.63,28.07,30.49$, $42.68,64.60,65.32,65.58,74.65,75.25,84.43,121.37$, $126.85,133.00,140.38,156.29,170.16$. IR $(\mathrm{KBr}), \mathrm{cm}^{-1}$ : $3330,2961,2872,1754,1692,1534,822$. Calcd for $\mathrm{C}_{42}$ $\mathrm{H}_{48} \mathrm{~N}_{2} \mathrm{O}_{8}: \mathrm{C}, 71.16 ; \mathrm{H}, 6.83 ; \mathrm{N}, 3.95$. Found: C, 71.04; H, $6.61 ; \mathrm{N}, 3.77$. 


\section{Solid-State Polymerization}

Solid-state polymerization of the monomers was done by UV or $\gamma$-radiation. UV-radiation was used for preliminary check of monomer reactivity toward 1,4-addition polymerization and measurement of absorption spectra. ${ }^{60} \mathrm{Co} \gamma$-radiation was conducted to convert bulk monomers, which were taken in glass tubes, evacuated and sealed, to the corresponding polymers. Irradiated dose was $500 \mathrm{kGy}$ for each sample. Conversion to polymer was determined by extracting the irradiated samples with monomer soluble solvent, i.e., boiling toluene for poly[4BCMU4A(PhF)] and chloroform for poly[4BCMU4$\mathrm{A}(\mathrm{Biph})$, and weighing the undissolved polymer portions. Polymer conversion percentage was calculated by comparing weights of the sample before and after extraction. Thin film samples were prepared as follows. Chloroform solution of monomers was spin-coated onto the quartz plate, and the polycrystalline monomer thin films were polymerized by a 16 -W UV-lamp ( $254 \mathrm{~nm}$ ) kept at 4 $\mathrm{cm}$ in front of the sample.

\section{RESULTS AND DISCUSSION}

\section{Solid-State Polymerization}

DAs 4BCMU4A(PhF) and 4BCMU4A(Biph) were polymerized in the solid state using $\gamma$-radiation as well as UV-rays. For samples irradiated by $500 \mathrm{kGy}$ of $\gamma$-ray, no monomers were found by monomer extraction indicating quantitative conversion to the polymers. Heating failed to polymerize the samples in the solid state. Contrary to the above two DAs, no solid-state polymerization was observed for $4 \mathrm{BCMU} 4 \mathrm{~A}(\mathrm{Ph})$ using any stimulus.

Since all diol precursors $6 \mathbf{a}-\mathbf{6 c}$ were not polymerized by UV irradiation, hydrogen bonding between urethane groups of adjacent monomers in $4 \mathrm{BCMU} 4 \mathrm{~A}(\mathrm{PhF})$ and 4BCMU4A(Biph) should help to align them in a polymerizable stack, as was observed in other cases. ${ }^{11-13,19}$ As an exception, 4BCMU4A(Ph) was not polymerized. For 1,4-bis(1,3-octadecadiynyl)benzene (BOB) with structure similar to $4 \mathrm{BCMU} 4 \mathrm{~A}(\mathrm{Ph})$ having simple alkyl group instead of AU group, there is a phase transition point at $300 \mathrm{~K}$ in crystalline state due to phenylene group flip. ${ }^{14}$ Therefore, regular 1,4-addition polymerization does not occur above $300 \mathrm{~K}$ though it is polymerized to give a PDA below this temperature. Since 4BCMU4A(Ph) does not show such transition points above room temperature below melting point as investigated by differential scanning calorimetry, it seems that there is no phenylene group flip for $4 \mathrm{BCMU} 4 \mathrm{~A}(\mathrm{Ph})$. The only molecular structural difference in crystal between $\mathrm{BOB}$ below $300 \mathrm{~K}$ and $4 \mathrm{BCMU} 4 \mathrm{~A}(\mathrm{Ph})$ is hydrogen bonding in $4 \mathrm{BCMU} 4 \mathrm{~A}(\mathrm{Ph})$. Thus, we presume that effective intermolecular hydrogen bonding together with plane-to-plane interaction of $\pi$-conjugated bis(butadiynyl)phenylene parts of adjacent $4 \mathrm{BCMU} 4 \mathrm{~A}(\mathrm{Ph})$ molecules may result in shorter stacking distance $d$ in crystals, which is not appropriate for solidstate polymerization as in Scheme 1. For the other two polymerizable monomers, repulsive interaction may be a favorable factor, i.e., electrostatic repulsion between electrically negative tetrafluorophenylene rings and/or dipole-dipole repulsion of polarized $\mathrm{C}-\mathrm{F}$ bonds for 4$\mathrm{BCMU} 4 \mathrm{~A}(\mathrm{PhF})$ and steric hindrance between biphenylene groups in twisted form for 4BCMU4A(Biph). These

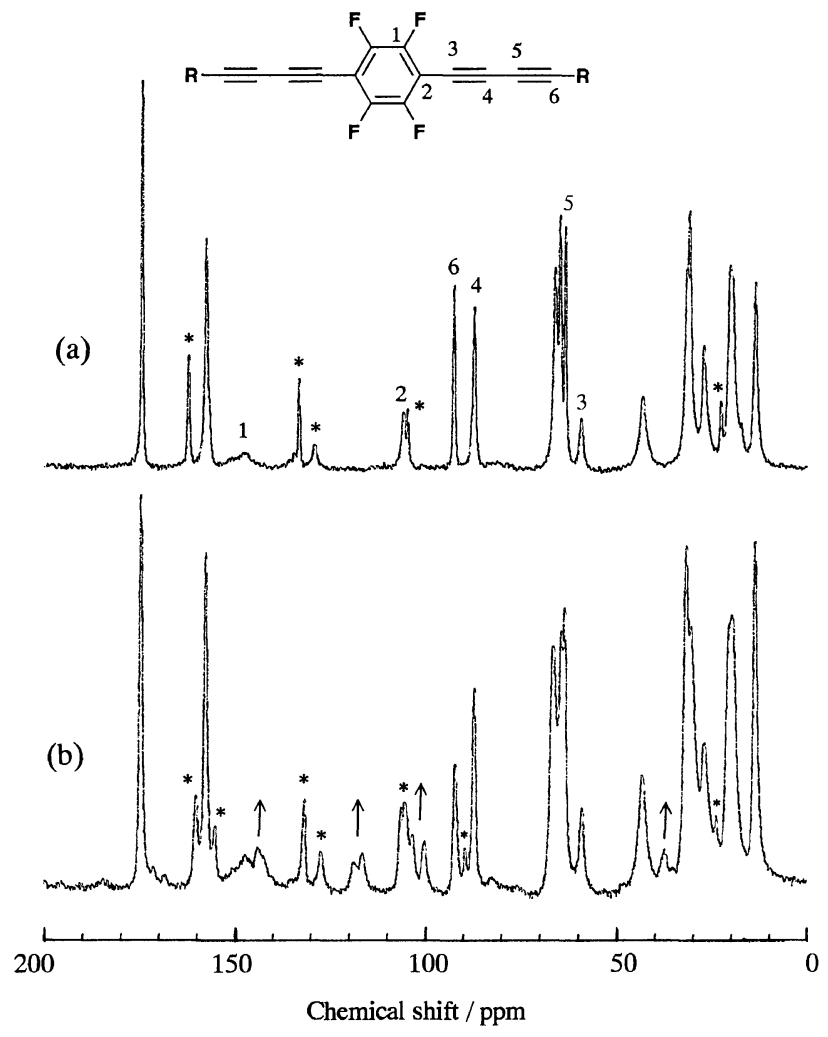

Figure 1. ${ }^{13} \mathrm{C}$ CP/MAS NMR spectra of (a) $4 \mathrm{BCMU} 4 \mathrm{~A}(\mathrm{PhF})$ monomer and (b) the sample irradiated with $\gamma$-ray (500 kGy). Asterisks indicate spinning side bands. Numbers on peaks in spectrum (a) are assignments of carbons, shown in the inserted chemical structure. Upward arrows in spectrum (b) are for new peaks due to PDA formation.

repulsive interactions together with attractive interaction of hydrogen bonding may properly tune the arrangement of molecules to polymerizable stacking. Though several PDAs with fluorinated aromatic rings directly bound to the main chain have been reported, ${ }^{22}$ PDA with biphenyl group directly bound to the main chain is the first example to be synthesized, to our knowledge.

\section{Polymer Structure}

To elucidate the structures of the polymers, ${ }^{13} \mathrm{C} \mathrm{CP} /-$ MAS NMR spectra were recorded. Assignment of ${ }^{13} \mathrm{C}$ peaks was performed based on the previous reports. ${ }^{14,23,24}$ Figure 1 shows CP/MAS spectra of 4BCMU$4 \mathrm{~A}(\mathrm{PhF})$ monomer and its polymer obtained after 500 $\mathrm{kGy}$ of $\gamma$-ray irradiation. In Figure 1a for the NMR spectrum of the monomer sample, peaks at $92,87,63$, and 59 ppm are assigned to four unequivalent acetylenic carbons of the monomer. The broad peak at $148 \mathrm{ppm}$ corresponds to fluorinated carbons of tetrafluorophenyl ring and the broadening is due to coupling between carbon and fluorine. The peak at $105 \mathrm{ppm}$ is for quaternary carbons of the aromatic ring, adjacent to acetylenic carbons. Figure $1 b$ is the spectrum of the fully polymerized polymer sample of $4 \mathrm{BCMU} 4 \mathrm{~A}(\mathrm{PhF})$ which exhibits several new peaks as indicated by the upward arrows. Peaks at 144 and $116 \mathrm{ppm}$ correspond to the two olefinic carbons of the polymer backbone. The appearance of two olefinic carbons at different chemical shifts is due to asymmetri- 
cal substitutions of PDA. Peaks at 100 and 103 ppm correspond to the two acetylenic carbons of the polymer backbone. The peak at $37 \mathrm{ppm}$ is for the methylene carbon adjacent to the olefinic carbon of polymer backbone. Remaining peaks at $92,87,63$, and 59 ppm are assigned to unreacted DA carbons in side group. Since the polymer sample was confirmed to contain no monomer by extraction, all monomer molecules are involved in PDA formation. Consequently, the above peaks for unreacted DA must be due to a DA moiety on one side of the monomer unit.

Figure 2 shows the CP/MAS spectra of 4BCMU4A(Biph) monomer and its polymer. Some signals, as single peaks in solution spectrum of the monomer, split into two peaks in solid state, e.g., peaks at 141 and $138 \mathrm{ppm}$ in the solid state derived from a peak at $140.38 \mathrm{ppm}$ in solution, peaks at 129 and $126 \mathrm{ppm}$ from a peak at $126.85 \mathrm{ppm}$, etc. These splits are due to fixed asymmetric structures in crystals or polymorphism of crystals. By careful assignment of peaks and spinning side bands in these spectra, spectral change of $4 \mathrm{BCMU} 4 \mathrm{~A}(\mathrm{Biph})$ while going from monomer to polymer was also found to be similar as in case of $4 \mathrm{BCMU} 4 \mathrm{~A}(\mathrm{PhF})$. The $4 \mathrm{BCMU} 4 \mathrm{~A}-$ (Biph) monomer shows acetylenic carbon peaks at 85 (splitting), 76, 74, 65 (overlapping with methylene carbons adjacent to oxygen atom) ppm. On polymerization, the peaks for two olefinic carbon of PDA backbone appear around $132 \mathrm{ppm}$. New peaks around 100-105 ppm can be assigned to acetylenic carbons of PDA backbone. Acetylenic peaks ranging from 65 to $85 \mathrm{ppm}$ in the fully polymerized sample are due to the unreacted DA section of $4 \mathrm{BCMU} 4 \mathrm{~A}(\mathrm{Biph})$.

Though the monomer FT-IR spectrum of 4BCMU4A(Biph) shows no strong peak related to $-\mathrm{C} \equiv \mathrm{C}-$ stretching vibration, that of $4 \mathrm{BCMU} 4 \mathrm{~A}(\mathrm{PhF})$ exhibits a corresponding peak at $2246 \mathrm{~cm}^{-1}$. On polymerization, the fully polymerized sample still showed peaks at $2246 \mathrm{~cm}^{-1}$. Thus, on the basis of CP/MAS and FT-IR results, we can follow the polymerization only in one step to give single- chain-type PDA in Scheme 2. Here, the polymer structure from the monomer stacking as shown in Scheme 4 is ruled out, because monomer arrangement like Scheme 4 has no aromatic plane-to-plane interaction nor the hydrogen bonding between adjacent often resulting in a

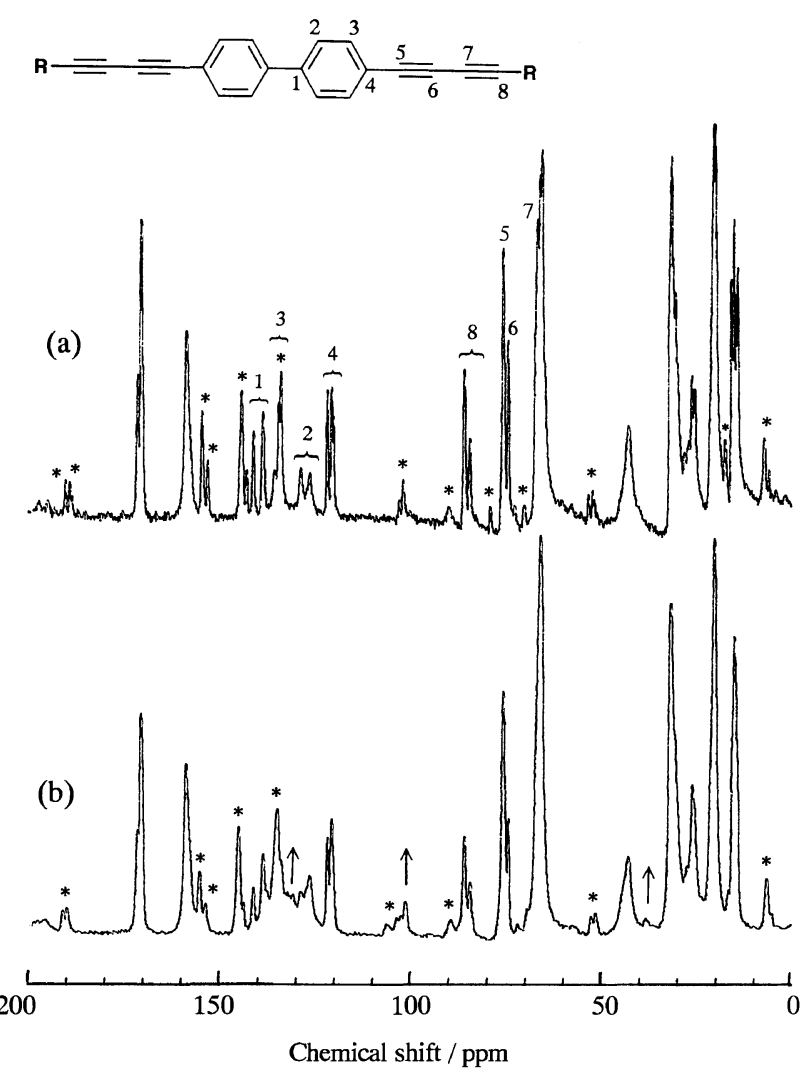

Figure 2. ${ }^{13} \mathrm{C}$ CP/MAS NMR spectra of (a) $4 \mathrm{BCMU} 4 \mathrm{~A}(\mathrm{Biph})$ monomer and (b) polymer obtained by $\gamma$-ray irradiation ( $500 \mathrm{kGy}$ ). Asterisks indicate spinning side bands. Numbers on peaks in spectrum (a) are assignments of carbons, shown in the inserted chemical structure. Upward arrows in spectrum (b) are for new peaks due to PDA formation.

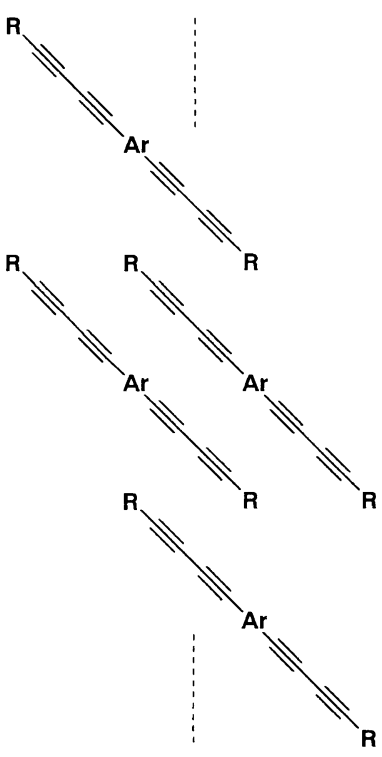

Monomer

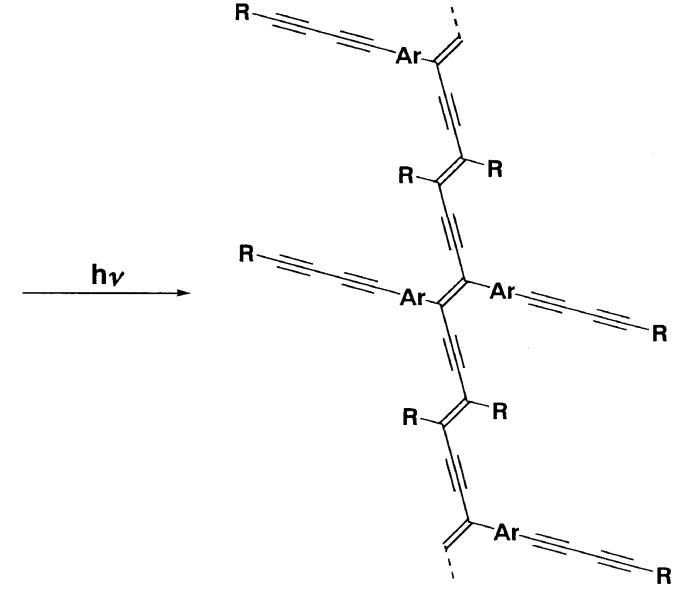

Another type of

Single-chain-type PDA

Scheme 4. Polymerization scheme for another possible monomer arrangement in 4BCMU4A(Ar) crystals. 


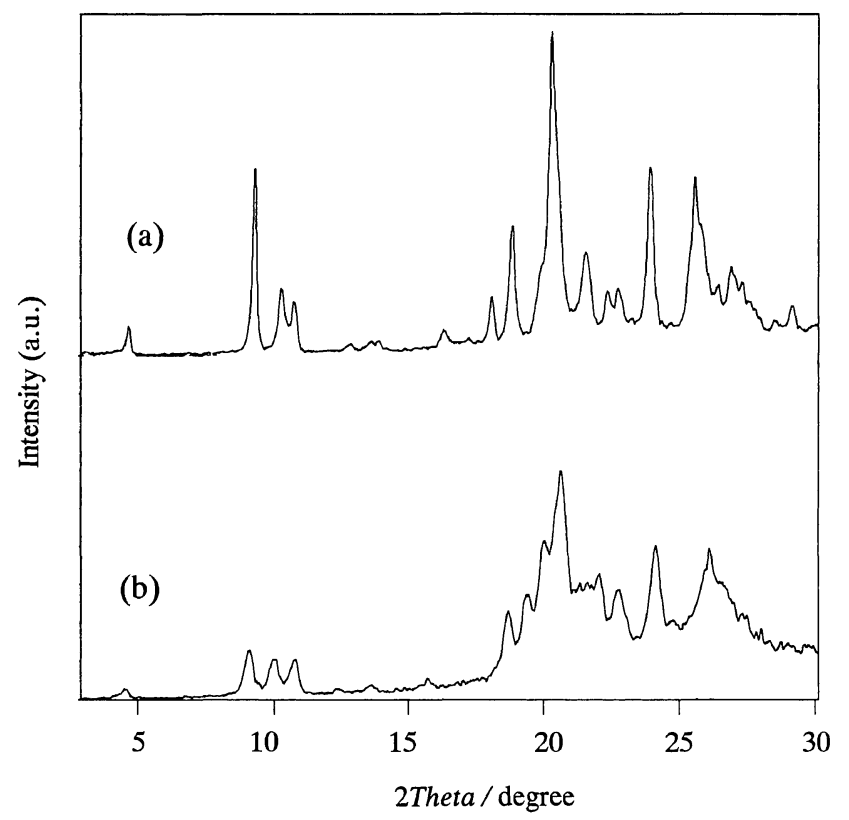

Figure 3. Powder XRD of (a) $4 \mathrm{BCMU} 4 \mathrm{~A}(\mathrm{PhF})$ monomer and (b) polymer obtained after $500 \mathrm{kGy} \gamma$-ray irradiation.

nonpolymerizable stack. Even if in a polymerizable stack, the polymer in Scheme 4 seems to have less crystallinity due to geometrical difficulty in the movement of atoms composing the monomer in the course of polymerization. Thus, powder XRD patterns for 4BCMU4A(PhF) monomer and its polymer obtained by irradiation with $500 \mathrm{kGy}$ of $\gamma$-ray were recorded as shown in Figure 3. The monomer of $4 \mathrm{BCMU} 4 \mathrm{~A}(\mathrm{PhF})$ is crystalline as seen in Figure 3a. X-Ray diffraction of the polymer suggests that crystallinity has been maintained in the course of polymerization. This was observed for powder XRD for the $4 \mathrm{BCMU} 4 \mathrm{~A}(\mathrm{Biph})$ sample. $4 \mathrm{BCMU} 4 \mathrm{~A}(\mathrm{Biph})$ was found to preserve its crystallinity without significant deterioration during polymerization (Figure 4). The polymer structure in Scheme 2 should thus be proper.

It may be mentioned that in our previous work on 1,4addition polymerization of $4 \mathrm{BCMU} 4 \mathrm{~A}(8),{ }^{11}$ which contains alkyl chain instead of aryl moiety in the central position of 4BCMU4A(Ar), polymerization was found to occur at both DA sections of the monomer. As a consequence, extra strain was generated as the ladder type polymer was formed and hence the crystallinity of the polymer was compromised. In the present cases, PDAs from both 4BCMU4A(Ar) monomers are formed by only one-step of 1,4-addition polymerization. So, it is expected that the strain factor caused by the movement of adjacent aromatic substituent as well as methylene chain is much less during polymerization. Hydrogen bonding between urethane groups of adjacent monomer molecules may maintain the crystallinity of respective polymers. Interaction between planar aromatic rings of the monomer molecules may help to keep the crystal lattice in proper condition during the transition from monomer to polymer. Due to the above factors, we obtained highly crystalline PDAs from $4 \mathrm{BCMU} 4 \mathrm{~A}(\mathrm{Ar})(\mathrm{Ar}=\mathrm{PhF}$ and Biph) derivatives with $\pi$-conjugation between polymer backbone and aromatic substituents. The reason why the second step of polymerization dose not proceed

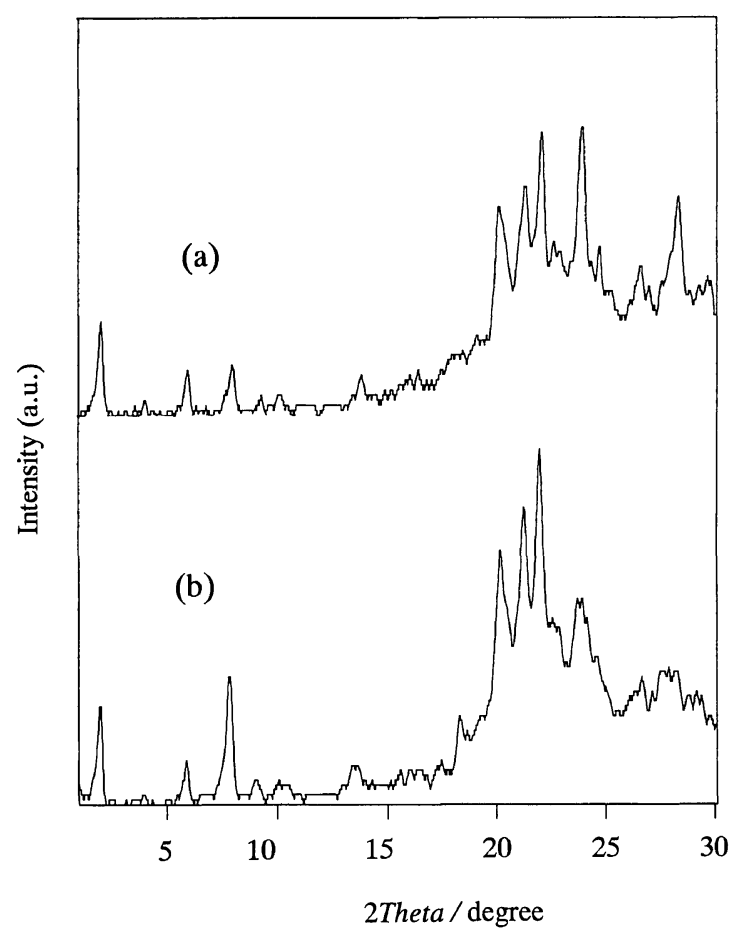

Figure 4. Powder XRD of (a) 4BCMU4A(Biph) monomer and (b) polymer obtained after $500 \mathrm{kGy} \gamma$-ray irradiation.

for the single-chain-type PDAs from 4BCMU4A(Ar) in spite of high crystallinity seems to be that the stacking distance $d$ and angle $\Phi$ shown in Scheme 1 for the remaining DA parts are not appropriate for 1,4-addition polymerization.

\section{Visible Absorption Spectra of the Polymers}

The electronic structures of PDAs obtained were expected to be quite interesting owing to the presence of long $\pi$-conjugated side chains. Visible absorption spectra were recorded for the polymers from 4BCMU4A$(\mathrm{PhF})$ and 4BCMU4A(Biph). Figure 5 shows absorption spectra for polycrystalline thin films of the polymers from 4BCMU4A(PhF) and 4BCMU4A(Biph). Characteristic excitonic absorption of PDA structure was observed for both PDA derivatives. Absorption maximum wavelengths $\left(\lambda_{\max } \mathrm{s}\right)$ for poly[4BCMU4A(PhF)] and poly[4BCMU4A(Biph)] were $593 \mathrm{~nm}$ and $640 \mathrm{~nm}$, respectively.

There is significant difference in $\lambda_{\text {max }}$ between poly[4$\mathrm{BCMU} 4 \mathrm{~A}(\mathrm{PhF})]$ and poly[4BCMU4A(Biph)]. This can be explained by referring to $\lambda_{\max }$ of a typical PDA compound, poly(4BCMU2A) $(\mathrm{R}-\mathrm{C} \equiv \mathrm{C}-\mathrm{C} \equiv \mathrm{C}-\mathrm{R}$, where $\mathrm{R}$ is AU group), whose $\lambda_{\max }$ is $620 \mathrm{~nm} .^{25}$ This polymer does not have aryl side groups attached to the PDA backbone and hence $\lambda_{\max }$ is due only to the PDA backbone. $\lambda_{\max }$ for poly[4BCMU4A(PhF)] blue-shifts by $27 \mathrm{~nm}$ more than that of poly(4BCMU2A). In this polymer, the electron-withdrawing group (tetrafluorophenyl group) attached to PDA backbone may cause electron density of PDA backbone to diminish, thus affecting the blue-shift. $\lambda_{\text {max }}$ for poly[4BCMU4A(Biph)] red-shifts by $20 \mathrm{~nm}$ more than that of poly(4BCMU2A). This may be due to electron donation from biphenyl group to the PDA backbone.

Of the above two polymers, poly[4BCMU4A(PhF)] uniformly dispersed in common organic solvents such as 

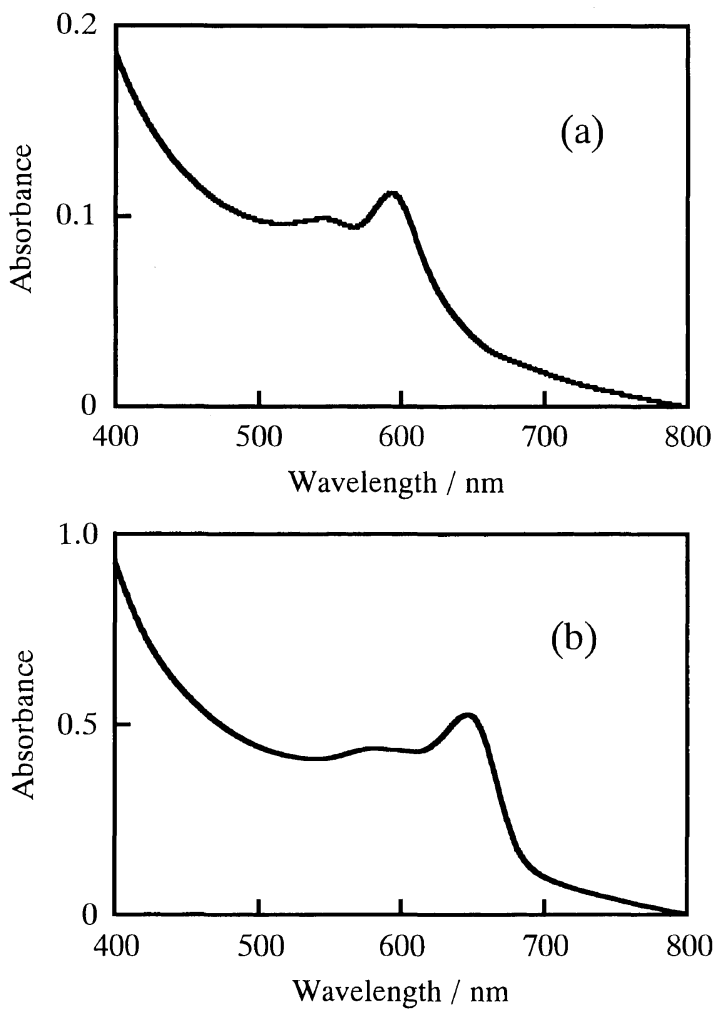

Figure 5. Visible absorption spectra of polycrystalline thin films of (a) poly[4BCMU4A(PhF)] and (b) poly[4BCMU4A(Biph)].

chloroform, tetrahydrofuran, and $N, N$-dimethylformide. The polymer did not dissolve in these organic solvents but dispersed because the dispersed polymer could not pass through the precolumn for gel permeation chromatography. From dynamic light scattering measurement, particle size was estimated as $60 \mathrm{~nm}$. The color of the polymer dispersion in chloroform was red. On addition of hexane, not a dispersing solvent for poly[4BCMU4A$(\mathrm{PhF})]$, the color of the dispersion changes to red-purple. This solvatochromic behavior has been reported for some PDA derivatives with AU groups. ${ }^{26}$ Further addition of hexane causes the polymer to precipitate out as a redpurple solid. Absorption spectra for poly[4BCMU4A$(\mathrm{PhF})$ ] dispersion in (a) chloroform and in (b) chloroformhexane $(1: 1)$ mixture are shown in Figure 6. For chloroform dispersion of poly[4-BCMU4A(PhF)], a broad peak around $490 \mathrm{~nm}$ along with a shoulder peak at $560 \mathrm{~nm}$ was observed. The polymer dispersed in chloroformhexane $(1: 1)$ mixture exhibits $\lambda_{\max }$ at $520 \mathrm{~nm}$ along with two shoulder peaks at $560 \mathrm{~nm}$ and $590 \mathrm{~nm}$. Change in absorption spectrum in Figures $6 \mathrm{a}$ and $6 \mathrm{~b}$ indicates that the conformational transition of PDA backbone takes place depending on the degree of interaction of chloroform with ester and urethane units of the side group. Increase in intensity of the peak at $560 \mathrm{~nm}$ and appearance of the new peak at $590 \mathrm{~nm}$ mean that conformation of PDA backbone in chloroform-hexane dispersion is close to that in the crystalline state.

From chloroform dispersion of poly[4BCMU4A(PhF)], we prepared an amorphous polymer thin film by the spin-coating method. This polymer film shows a broad absorption peak at $542 \mathrm{~nm}$ without shoulders as shown in Figure 6c. When $\lambda_{\max }$ is used as an index for averaged

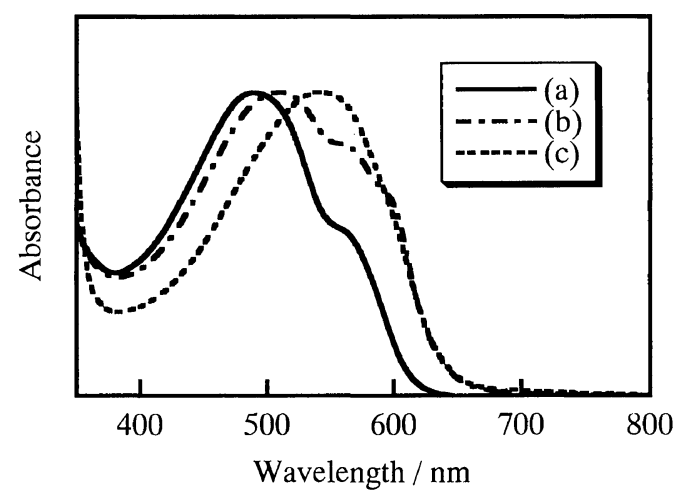

Figure 6. Visible absorption spectra for poly[4BCMU4A(PhF)] in (a) chloroform solution, (b) chloroform-hexane (1:1) mixture solution, and (c) an amorphous thin film state. Absorbance is normalized by that at absorption maximum.

extension of $\pi$-conjugation, the order obtained from more extended to less extended conjugation is crystalline film, amorphous film, dispersion in chloroformhexane mixture, and dispersion in chloroform. This may be explained by assuming the $\pi$-conjugated backbone of PDA to acquire a nonplanar conformation in the dispersion state due to interaction between the solvent and side groups. In the crystalline state, the PDA backbone assumes a planar conformation due to interaction between adjacent side groups by hydrogen bonding. The structure in the amorphous state is generally considered between dispersion and crystalline states, and this is true for the present case.

\section{CONCLUSION}

DA monomers (4BCMU4A(Ar)), in which the aryl group is sandwiched by two butadiynyl moieties, were prepared. 4BCMU4A $(\mathrm{Ph})$ did not show solid-state polymerization by any stimulus used. $4 \mathrm{BCMU} 4 \mathrm{~A}(\mathrm{PhF})$ and 4BCMU4A(Biph) underwent one-step 1,4-addition reaction to give the respective PDAs having 4-(butadiynyl)aryl moieties as side chains. Polymer structures were confirmed by spectral studies. From XRD measurement, the crystallinity of $4 \mathrm{BCMU} 4 \mathrm{~A}(\mathrm{PhF})$ and $4 \mathrm{BCMU} 4 \mathrm{~A}-$ (Biph) was maintained during polymerization possibly due to effects of interactions between adjacent aromatic moieties. Thus, we prepared highly crystalline PDA with aryl moieties as side chains. Further polymerization of the remaining DA segment of these polymers was impossible by $\gamma$-ray irradiation and thus the corresponding ladder polymers were not obtained. PDAs obtained from 4BCMU4A(PhF) and 4BCMU4A(Biph) showed $\lambda_{\text {max }}$ at $593 \mathrm{~nm}$ and $640 \mathrm{~nm}$, respectively, in accordance with electronic properties of central aryl moiety. Interestingly, the polymer of $4 \mathrm{BCMU} 4 \mathrm{~A}(\mathrm{PhF})$ was dispersed in some organic solvents. In chloroform dispersion, conformational transition of PDA backbone was observed by adding hexane, which depended on interaction between the solvent and ester and urethane units of the side group.

\section{REFERENCES}

1. G. Wegner, Z. Naturforsch. B: Chem. Sci., 24, 824 (1969); D. 
Bloor and R. R. Chance, Ed., "Polydiacetylenes", NATO ASI Ser. E, Appl. Sci., Martin Nijhoff Publishers, Dordrecht, The Netherlands, 1985 vol. 102.

2. S. Okada, H. Matsuda, and H. Nakanishi, in "Polymeric Materials Encyclopedia”, J. C. Salamone, Ed., CRC Press, Boca Raton, FL, 1996, p 8393.

3. G. M. J. Schmidt, in "Reactivity of the Photoexcited Organic Molecule”, John Wiley \& Sons, Inc., New York, N.Y., 1967, p 227; R. H. Baughman, J. Polym. Sci., Polym. Phys. Ed., 12, 1511 (1974).

4. H. J. Cantow, Ed., "Polydiacetylenes", Adv. Polym. Sci., Springer-Verlag GmbH \& Co., Berlin, 1984 vol. 63

5. K. J. Donovan and E. G. Wilson, Philos. Mag. B, 44, 9 (1981),

6. G. N. Patel, R. R. Chance, and J. D. Witt, J. Polym. Sci., Polym. Lett. Ed., 16, 607 (1978); K. C. Lim, C. R. Fincher, S. A. Casalnuovo, and A. J. Heeger, Mol. Cryst. Liq. Cryst., 105, 329 (1984).

7. C. Sauteret, J. P. Hermann, R. Frey, F. Pradère, J. Ducuing, R. H. Baughman, and R. R. Chance, Phys. Rev. Lett., 36, 956 (1976).

8. G. M. Carter, M. K. Thakur, Y. J. Chen, and J. V. Hryniewicz, Appl. Phys. Lett., 47, 457 (1985); F. Kajzar and J. Messier, Thin Solid Films, 132, 11 (1985).

9. S. Molyneux, H. Matsuda, A. K. Kar, B. J. Wherrett, S. Okada, and H. Nakanishi, Nonlinear Opt., 4, 229 (1993).

10. B. L. Lawrence, M. Cha, J. U. Kang, W. Torruellas, G. Stegeman, G. Baker, J. Meth, and S. Etemad, Electron. Lett., 30, 447 (1994)

11. H. Matsuzawa, S. Okada, H. Matsuda, and H. Nakanishi, Chem. Lett., 1997, 1105; H. Matsuzawa, S. Okada, H. Matsuda, and H. Nakanishi, Mol. Cryst. Liq. Cryst., 315, 129 (1998). The units of $\gamma$-ray dosage for solid-state polymerization described in these two references should be corrected to MGy; H. Matsuzawa, S. Okada, A. Sarkar, H. Matsuda, and H. Nakanishi, J. Polym. Sci., Part A: Polym. Chem., 37, 3537 (1999).

12. S. Okada, K. Hayamizu, H. Matsuda, A. Masaki, N. Minami, and H. Nakanishi, Macromolecules, 27, 6259 (1994).

13. H. Matsuzawa, S. Okada, H. Matsuda, and H. Nakanishi, Proc. SPIE , 2851, 14 (1996)

14. W. S. Price, N. Kikuchi, H. Matsuda, K. Hayamizu, S. Okada, and H. Nakanishi, Macromolecules, 28, 5363 (1995).

15. B. J. Orchard and S. K. Tripathy, Macromolecules, 19, 1844
(1986); S. B. Clough, S. Kumar, X. F. Sun, S. K. Tripathy, H. Nakanishi, H. Matsuda, S. Okada, and M. Kato, in "Nonlinear Optics of Organics and Semiconductors", Springer Proc. Phys., T. Kobayashi, Ed., Springer-Verlag GmbH \& Co., Berlin, 1989, 36, p 149.

16. H. Nakanishi, S. Okada, H. Matsuda, and M. Kato, in "Frontiers of Macromolecular Science", T. Saegusa, T. Higashimura, and A. Abe, Ed., Blackwell Scientific Publications Ltd., Oxford, 1989, p 469; S. S. Talwar, M. Kamath, K. Das, and U. C. Sinha, Polym. Commun., 31, 198 (1990); A. Sarkar, S. Okada, H. Nakanishi, and H. Matsuda, Macromolecules, 31, 9174 (1998).

17. S. Okada, K. Hayamizu, H. Matsuda, A. Masaki, and H. Nakanishi, Bull. Chem. Soc. Jpn., 64, 857 (1991).

18. H. Nakanishi, H. Matsuda, S. Okada, and M. Kato, Polym. Adv. Technol., 1, 75 (1990)

19. S. Okada, T. Doi, A. Mito, K. Hayamizu, A. Ticktin, H. Matsuda, N. Kikuchi, A. Masaki, N. Minami, K.-H. Haas, and H. Nakanishi, Nonlinear Opt., 8, 121 (1994).

20. D. D. Perrin, W. L. F. Armarego, and D. R. Perrin, "Purification of Laboratory Chemicals" 2nd ed, Pergemon Press, Oxford, 1980

21. S. Okada, H. Matsuda, A. Masaki, H. Nakanishi, and K. Hayamizu, Proc. SPIE , 1560, 25 (1991)

22. H. Nakanishi, H. Matsuda, S. Okada, and M. Kato, in "Nonlinear Optics of Organics and Semiconductors", Springer Proc. Phys., T. Kobayashi, Ed., Springer-Verlag GmbH \& Co., Berlin, 1989, 36, p 155

23. K. Hayamizu, S. Okada, T. Doi, H. Kawanami, N. Kikuchi, H. Matsuda, and H. Nakanishi, Bull. Chem. Soc. Jpn., 68, 791 (1995); S. Okada, T. Doi, N. Kikuchi, K. Hayamizu, H. Matsuda, and H. Nakanishi, Mol. Cryst. Liq. Cryst., 247, 99 (1994).

24. K. Hayamizu, M. Yanagisawa, and O. Yamamoto, NMR spectral database included in "Integrated Spectral Data Base System for Organic Compounds": http://www.aist.go.jp/RIODB/ SDBS/

25. G. N. Patel, Polym. Prepr., Am. Chem. Soc., Div. Polym. Chem., 19 (2), 154 (1978).

26. G. N. Patel, R. R. Chance, and J. D. Witt, J. Polym. Sci., Polym. Phys. Ed., 16, 607 (1978); N. B. Kodali, W. Kim, J. Ku mar, S. K. Tripathy, and S. S. Talwar, Macromolecules, 27, 6612 (1994). 